\title{
Transplant Education Practices and Attitudes in Dialysis Centers:
}

\section{Dialysis Leadership Weighs In}

\author{
Amy D. Waterman ${ }^{1 *}$, Christina Goalby ${ }^{1}$, Shelley S. Hyland ${ }^{1}$, Melanie McCabe ${ }^{1}$ and Katrina M. Dinkel ${ }^{2}$ \\ ${ }^{1}$ Department of Internal Medicine, Washington University School of Medicine, 660 S. Euclid Ave, Campus Box 8005, St. Louis, MO 63110, USA \\ ${ }^{2}$ Executive Director, Heartland Kidney Network, 559 NW Barry Rd, \#348, Kansas City, MO 64154, USA
}

\begin{abstract}
When senior leadership endorses quality improvement priorities, their staff is more likely to comply. To honor Centers for Medicare and Medicaid Services's (CMS) mandates, dialysis clinic managers must ensure that transplant education takes place within their centers. We surveyed 131 dialysis clinic managers in End Stage Renal Disease (ESRD) Network 12 (the Heartland Kidney Network) to understand their transplant attitudes, knowledge, active educational programs, and perceived barriers to transplant. Few reported that there was a designated transplant educator $(40 \%)$ or formal transplant education program (33\%) available at their dialysis centers. Transplant education most commonly occurring with all patients included educators (53\%) or physicians (49\%) discussing transplant with the patient, giving them handouts or brochures $(40 \%)$, the transplant center phone numbers $(36 \%)$, and referring them to other transplant educational resources $(22 \%)$. Over half were dissatisfied with transplant education available $(56 \%)$ and felt that their educators did not have sufficient time to educate $(57 \%)$. Most did not know that a kidney transplant from a living donor is expected to last $15-20$ years (78\% incorrect) or that almost $90 \%$ of kidneys function for at least one year (71\% incorrect). Managers with formal transplant education programs in their dialysis centers were more likely to report that their patients were talking to educators $\left(80 \%\right.$ vs. $\left.49 \%, x^{2}=11.13, p<.01\right)$ and given handouts or brochures about transplant $\left(67 \%\right.$ vs. $\left.33 \%, x^{2}=14.63, p<.01\right)$. Unless dialysis corporations implement specific transplant education policies and procedures, transplant centers support these initiatives, and CMS ensures compliance, transplant education within dialysis centers will be intermittent.
\end{abstract}

Keywords: Kidney transplant; Patient education; Dialysis centers

Abbreviations: Deceased Donor Kidney Transplant (DDKT); Living Donor Kidney Transplant (LDKT); Centers For Medicare And Medicaid Services (CMS); End-Stage Renal Disease (ESRD)

\section{Introduction}

Although the survival, quality-of-life, and cost-saving benefits of Deceased Donor Kidney Transplant (DDKT) and Living Donor Kidney Transplant (LDKT) over remaining on lifetime dialysis are clearly established[1-6], dialysis patients who never present for evaluation at a transplant center may never have the opportunity to make an informed transplant choice. Thus, Centers for Medicare and Medicaid Services's (CMS) Conditions for Coverage for End-Stage Renal Disease (ESRD) facilities mandate that accredited dialysis centers provide evidence of transplant education [7]. Unfortunately, CMS data has revealed that less than $25 \%$ of physicians in dialysis clinics reported informing every patient about their deceased and living kidney donor transplant options [8]. Older, obese, uninsured and Medicaid-insured patients are less likely to be informed about transplant when they first begin dialysis [9]. Also, compared to Whites, studies have shown that patients who are members of ethnic/minority groups are less likely to be educated about transplantation [10-13] due to cultural or language barriers [14] or healthcare provider beliefs that minorities or individuals of low socioeconomic status may be more likely to drop out of evaluation or be unable to afford the immunosuppressant drugs $[15,16]$.

A variety of transplant education resources and programs are available nationally [17-20], some of which have shown significant improvements in ESRD patients' informed transplant decisionmaking, knowledge, and pursuit of transplant [21-25]. However, for these types of transplant educational programs to be effective, they have to reach transplant referral candidates consistently.

Research on the implementation of quality improvement interventions within healthcare settings has revealed that the attitudes and decision-making of key leadership is critical to ensuring active participation of staff [26-28]. Thus, dialysis clinic managers are critical partners for ensuring that transplant education is available for the $70 \%$ of ESRD patients on dialysis in the US $[29,30]$. Specifically, clinic managers ensure that educator's time is protected to enable transplant education to occur, especially in the first 45 days of starting dialysis, that financial resources are available to purchase transplant education, if needed, and that detailed tracking of patients' transplant referral status and transplant preferences are recorded in medical records in the case of a CMS audit.

However, there are currently no studies of key opinion leaders in dialysis that elucidate their transplant attitudes, knowledge, and perceived barriers to transplant within their centers. Therefore, we conducted an exploratory study of 131 dialysis clinic managers in a region managing the care and transplant education of over 13,000 patients to understand what is occurring educationally for patients, what barriers exist, and what improvements might assist their centers in educating and referring more patients for transplant. We also compared the educational practices occurring in dialysis centers with and without formal transplant education programs.

*Corresponding author: Amy D. Waterman, PhD, Department of Internal Medicine, Washington University School of Medicine, $660 \mathrm{~S}$. Euclid Ave, Campus Box 8005, St. Louis, MO 63110, USA, Tel: 314-454-8102; Fax: 314-362-8311; E-mail: awaterma@dom.wustl.edu

Received May 09, 2012; Accepted June 25, 2012; Published June 27, 2012

Citation: Waterman AD, Goalby C, Hyland SS, McCabe M, Dinkel KM (2012) Transplant Education Practices and Attitudes in Dialysis Centers: Dialysis Leadership Weighs In. J Nephrol Therapeutic S4:007. doi:10.4172/2161-0959.S4007

Copyright: @ 2012 Waterman AD, et al. This is an open-access article distributed under the terms of the Creative Commons Attribution License, which permits unrestricted use, distribution, and reproduction in any medium, provided the original author and source are credited. 


\section{Materials and Methods}

\section{Participants and procedure}

In 2008, prior to the changes in CMS no possessive Conditions for Coverage [7], we surveyed 131 dialysis clinic managers attending the Heartland Kidney Conference and Annual Business Meeting about their transplant educational practices. The Heartland Kidney Network (ESRD Network 12) monitors the quality of chronic kidney disease; dialysis, and transplant care for 264 dialysis centers in Missouri, Kansas, Iowa, and Nebraska. At the time of the survey, CMS Conditions for Coverage mandated that all dialysis centers encourage transplantation for patients who were medically and psychologically suitable candidates and inform patients of their suitability for transplantation [7].

The survey was administered to all attendees before the first educational session started. Participants were given 15 minutes to complete the questionnaire and received no compensation for participating. The study received IRB approval from Washington University School of Medicine.

\section{Survey measures}

The 65-question survey measured clinic manager and dialysis center characteristics, the process of delivering transplant education at each dialysis center, and whether different resources would be helpful to clinic managers in administering transplant education at their facilities. Survey questions on clinic managers' transplant knowledge were taken from a published instrument previously used to assess kidney patients' transplant knowledge [31]. The survey is available from the principal investigator upon request.

Transplant attitudes and knowledge: When asked to consider only their patients eligible for transplant referral, clinic managers were asked their level of agreement with eight attitudinal statements about transplant (e.g., "Transplant is a better medical option than dialysis") using a 5-point Likert scale ranging from 'strongly agree' (1) to 'strongly disagree' (5). They also answered eight multiple-choice questions about their knowledge about transplant (e.g., "On average, how many years is a kidney transplant from a living donor expected to last?").

Transplant education currently provided: Managers were asked how many patients in their center were transplant candidates, who educated dialysis patients about transplant, and how regularly this education was repeated. They were asked whether there was a formal transplant education program and if so, how often 13 different types of transplant education resources were utilized (e.g., Patients are shown a video discussing transplant) using a 3-point Likert scale (i.e., 'not used,' 'used with some patients,' 'used with all patients').

Need for additional support from transplant centers: They were also asked whether 14 potential barriers to transplant education, including confusion about which dialysis patients were eligible for transplant referral, insufficient transplant medical training, poor quality of transplant educational materials, lack of partnership with transplant centers, patient drop-out from transplant, and insufficient time to educate affected their centers' educational practices using a 4-point Likert scale (i.e., 'strongly agree' to 'strongly disagree'). Finally, they were asked whether continuing education about transplant would be helpful to them and other dialysis staff.

\section{Data analysis}

Using the Statistical Package for the Social Sciences Version 16.0 (SPSS Inc., Chicago, IL), we conducted basic descriptive and frequency analyses to assess clinic managers' transplant attitudes and knowledge, to understand how transplant education was being presented across the Network, and to determine what additional support resources would be most helpful. We compared differences in clinic managers' transplant attitudes, knowledge, barriers, and specific education practices for centers' with and without formal education programs using chi-squared tests.

\section{Results and Discussion}

\section{Participants}

At the end of 2007, of the 20,301 ESRD patients in the Heartland Kidney Network, there were 13,149 patients on dialysis and 2,337 patients (18\%) on the transplant waiting list [32]. In addition, 656 patients had received deceased or living donor transplants during 2007 [33]. Of 264 dialysis centers in the Heartland Kidney Network, 79\% sent a representative to attend the Heartland Kidney Conference and Annual Business Meeting.

Of the 306 dialysis providers in attendance from these dialysis centers, we received completed surveys from 287 attendees (Response Rate: $94 \%)$. In order to examine the opinions of administrators only, we excluded non-administrators [64 nurses, 22 dieticians, 41 social workers, 9 dialysis technicians and 20 others], leaving a final sample of 131 clinic managers.

Clinic managers attending the conference were predominantly nurse managers (62\%), female (92\%), and White (92\%). They had worked with dialysis patients for a median of 11 years (Interquartile Range: 7-17) (Table 1). Their dialysis centers varied in size, with a median caseload of 50 dialysis patients per center (IQR: 30-115). Forty-six percent of managers worked in dialysis centers where at least a fourth of the patients were racial/ethnic minorities.

\section{Administrators' transplant attitudes and knowledge}

Almost all clinic managers agreed that transplants could improve patients' health (97\%) and quality-of-life (97\%), with $87 \%$ agreeing that transplant is a better medical option than dialysis (Table 2). Managers were more likely to agree that dialysis patients should get on the

\begin{tabular}{|c|c|c|}
\hline \multicolumn{2}{|c|}{ Dialysis Center Manager Characteristics } & $\#(\%)$ \\
\hline Gender & $\begin{array}{l}\text { Female } \\
\text { Male }\end{array}$ & $\begin{array}{c}121(92 \%) \\
10(8 \%)\end{array}$ \\
\hline Race & $\begin{array}{l}\text { White } \\
\text { African-American } \\
\text { Asian } \\
\text { Did not report }\end{array}$ & $\begin{array}{c}121(92 \%) \\
6(5 \%) \\
2(1.5 \%) \\
2(1.5 \%)\end{array}$ \\
\hline Job Responsibilities & $\begin{array}{l}\text { Nurse Manager } \\
\text { Facility Administrator } \\
\text { Area Manager } \\
\text { Other manager (quality, clinic } \\
\text { operation officer, unit coordinator, } \\
\text { director of nursing) }\end{array}$ & $\begin{array}{c}81(62 \%) \\
41(31 \%) \\
5(4 \%) \\
4(3 \%)\end{array}$ \\
\hline \multicolumn{2}{|c|}{$\begin{array}{l}\text { Median years working with dialysis patients (Interquartile } \\
\text { Range) }\end{array}$} & $\begin{array}{l}11 \text { years } \\
(7-17)\end{array}$ \\
\hline \multicolumn{3}{|c|}{ Dialysis Center Characteristics } \\
\hline \multicolumn{2}{|c|}{$\begin{array}{l}\text { Median number of patients managed at center (Interquartile } \\
\text { Range) }\end{array}$} & $\begin{array}{c}50 \text { patients } \\
(30-115)\end{array}$ \\
\hline $\begin{array}{l}\text { Percentage of } \\
\text { patients who } \\
\text { are racial/ethnic } \\
\text { minorities }\end{array}$ & $\begin{array}{l}0 \%-25 \% \\
26 \%-50 \% \\
51 \%-75 \% \\
76 \%-100 \% \\
\text { Don't know }\end{array}$ & $\begin{array}{c}71(54 \%) \\
26(20 \%) \\
12(9 \%) \\
12(9 \%) \\
10(8 \%)\end{array}$ \\
\hline
\end{tabular}

Table 1: Administrator and Dialysis Center Characteristics. 
waiting list (86\%) than look for a living donor (78\%). One-third either disagreed or had no opinion about the statement, "living donation is a better medical option than deceased donation."

We examined dialysis center practices for tracking patients' eligibility for transplant referral. A significant proportion of managers (40\%) disagreed with the statement that they were certain which patients were eligible for transplant referral (Table 3). Also, 33\% reported that they did not know or did not have a regularly updated list of patients from their center who were on the deceased donor waiting list. Many clinic managers did not know how many of their patients received deceased (23\% did not know) or living donor transplants $(27 \%)$ in the previous year.

The majority disagreed that their medical training adequately covered transplant (77\%) and that they were sufficiently knowledgeable about transplant to answer most patients' questions (52\%). On average, clinic managers were only able to answer four of the eight basic transplant questions correctly (54\% correct). The majority did not

\begin{tabular}{|c|c|c|c|}
\hline $\begin{array}{l}\text { Transplant Attitudes (For my } \\
\text { transplant-eligible patients, } \\
\text { in general, I believe that...) }\end{array}$ & $\begin{array}{l}\text { Strongly Agree/ } \\
\text { Agree }\end{array}$ & $\begin{array}{l}\text { No Opin- } \\
\text { ion }\end{array}$ & $\begin{array}{l}\text { Strongly } \\
\text { Disagree/ } \\
\text { Disagree }\end{array}$ \\
\hline $\begin{array}{l}\text { Transplants could improve their } \\
\text { health. }\end{array}$ & $127(97 \%)$ & $4(3 \%)$ & 0 \\
\hline $\begin{array}{l}\text { Transplants could improve their } \\
\text { quality-of-life. }\end{array}$ & $127(97 \%)$ & $4(2 \%)$ & 0 \\
\hline $\begin{array}{l}\text { Transplant is a better medical } \\
\text { option than dialysis. }\end{array}$ & $114(87 \%)$ & $13(10 \%)$ & $4(3 \%)$ \\
\hline $\begin{array}{l}\text { They should get on the de- } \\
\text { ceased donor waiting list. }\end{array}$ & $113(86 \%)$ & 17 (13\%) & $1(1 \%)$ \\
\hline $\begin{array}{l}\text { They should look for a living } \\
\text { donor. }\end{array}$ & $102(78 \%)$ & $23(17 \%)$ & $6(5 \%)$ \\
\hline $\begin{array}{l}\text { Living donation is a better } \\
\text { medical option than deceased } \\
\text { donation. }\end{array}$ & $86(66 \%)$ & $38(29 \%)$ & $7(5 \%)$ \\
\hline $\begin{array}{l}\text { They should not involve a living } \\
\text { donor because it is too risky to } \\
\text { a donor's health. }\end{array}$ & $9(7 \%)$ & $30(23 \%)$ & $92(70 \%)$ \\
\hline Transplant Knowledge & \multicolumn{3}{|l|}{ \# Correct (\%) } \\
\hline $\begin{array}{l}\text { Patients over age } 65 \text { are not } \\
\text { too old to be eligible for a } \\
\text { transplant. }\end{array}$ & \multicolumn{3}{|l|}{$117(89 \%)$} \\
\hline $\begin{array}{l}\text { Rich patients are no more likely } \\
\text { to get kidney from deceased } \\
\text { donor list compared to poor } \\
\text { patients. }\end{array}$ & \multicolumn{3}{|l|}{$92(70 \%)$} \\
\hline $\begin{array}{l}\text { Living donors do not have to } \\
\text { pay for testing and hospitaliza- } \\
\text { tion related to kidney donation. }\end{array}$ & \multicolumn{3}{|l|}{$84(64 \%)$} \\
\hline $\begin{array}{l}\text { The government pays for the } \\
\text { cost of transplant medications } \\
\text { for most recipients for } 3 \text { years. }\end{array}$ & \multicolumn{3}{|l|}{$73(56 \%)$} \\
\hline $\begin{array}{l}\text { The chance that a kidney } \\
\text { recipient or living donor would } \\
\text { die while undergoing transplant } \\
\text { surgery is less than } 1 \% \text {. }\end{array}$ & \multicolumn{3}{|l|}{$69(53 \%)$} \\
\hline $\begin{array}{l}\text { Patients generally wait 3-5 } \\
\text { years on the waiting list for a } \\
\text { kidney from someone who has } \\
\text { died. }\end{array}$ & \multicolumn{3}{|l|}{$62(47 \%)$} \\
\hline $\begin{array}{l}87 \% \text { of all kidney transplants } \\
\text { work for at least } 1 \text { year. }\end{array}$ & \multicolumn{3}{|l|}{$38(29 \%)$} \\
\hline $\begin{array}{l}\text { A kidney transplant from a } \\
\text { living donor is expected to last } \\
15-20 \text { years. }\end{array}$ & \multicolumn{3}{|l|}{$29(22 \%)$} \\
\hline Mean Total Correct & \multicolumn{3}{|l|}{4.3 out of $8(54 \%)$} \\
\hline
\end{tabular}

Table 2: Administrators' Transplant Attitudes and Knowledge. know that a kidney transplant from a living donor is expected to last $15-20$ years (78\% incorrect), that almost $90 \%$ of kidneys function for at least one year after transplant ( $71 \%$ incorrect), or that patients in this region wait for a deceased donor kidney for an average of 3-5 years (53\% incorrect). There were no significant differences in transplant attitudes or knowledge between clinic managers in centers with and without formal transplant education programs in operation.

\section{Available transplant education in dialysis centers}

Transplant education was conducted by multiple staff members, most commonly nurses (72\%), social workers (64\%), and physicians (48\%). Only $40 \%$ of clinic managers reported that there was a designated transplant educator at their centers. Fifty-seven percent felt that educators did not have sufficient time to provide transplant education to all patients.

Eighty-six percent reported that transplant information was provided at least once to all patients eligible for transplant referral, whether patients expressed interest in transplant or not, with $56 \%$ reporting that this education was repeated annually (Table 4). The transplant education process for all patients commonly consisted of social workers $(53 \%)$ or physicians $(49 \%)$ discussing transplant with the patient, giving them handouts or brochures $(40 \%)$, the transplant center phone numbers (36\%), and referring them to outside transplant educational resources $(22 \%)$. Only a minority of dialysis centers had transplant information in the waiting room (24\% did) or provided patients with an opportunity to speak with a kidney recipient (9\%) or a living donor (7\%). Few centers had transplant (13\% did) or living donor meetings (4\%) involving patients' family members or friends.

Only $33 \%$ of clinic managers reported having a formal transplant program in operation at their centers. Managers with formal transplant education programs in place were more likely to report that their patients were talking to a social worker ( $80 \%$ vs. $49 \%, \chi 2=11.13, \mathrm{p}<.01$ ), given handouts or brochures about transplant ( $67 \%$ vs. $33 \%, \chi 2=14.63$, $\mathrm{p}<.01$ ), given a list of websites ( $27 \%$ vs. $8 \%, \chi 2=11.69, \mathrm{p}<.01$ ), and given all transplant center phone numbers ( $55 \%$ vs. $33 \%, \chi 2=9.36, \mathrm{p}<.01$ ).

The majority were dissatisfied with the quality of the education materials about deceased donation (56\% dissatisfied) and living donation $(63 \%)$ available at their centers. Transplant education provided to patients generally came from transplant centers (56\%), the National Kidney Foundation (53\%), or Heartland Kidney Network (32\%). Also, compared to dialysis centers with formal education programs, clinic managers without transplant education programs were less satisfied with available deceased $(40 \%$ vs. $63 \%$ dissatisfied, $\chi 2=5.41, \mathrm{p}<.05)$ and living donation education materials ( $49 \%$ vs. $68 \%$ dissatisfied, $\chi 2=4.03, \mathrm{p}<.05$ )

\section{Relationship between dialysis and transplant centers}

Only $1 \%$ of clinic managers agreed that their dialysis center did not want to lose patients to transplant. Although most agreed that the transplant center staff was helpful when they had questions (82\%), some felt that communication between dialysis and transplant centers was poor ( $42 \%$ agreed) or that the transplant staff was difficult to reach $(22 \%)$. There were no differences in clinic managers' attitudes regarding transplant center partnership based on whether they had a transplant education program in operation. However, clinic managers with formal transplant education programs in their dialysis centers were less likely to report difficulties reaching the transplant center staff compared to managers without formal programs (62\% vs. $81 \%$ had difficulties, $\chi 2=4.81, \mathrm{p}<.05)$. 
Citation: Waterman AD, Goalby C, Hyland SS, McCabe M, Dinkel KM (2012) Transplant Education Practices and Attitudes in Dialysis Centers: Dialysis Leadership Weighs In. J Nephrol Therapeutic S4:007. doi:10.4172/2161-0959.S4-007

Page 4 of 8

\begin{tabular}{|c|c|c|c|}
\hline \multicolumn{2}{|l|}{ 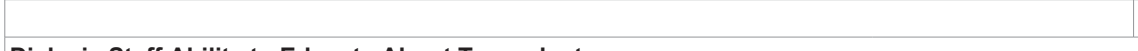 } & Strongly Agree/Agree & Strongly Disagree/ Disagree \\
\hline \multicolumn{4}{|l|}{ Dialysis Staff Ability to Educate About Transplant } \\
\hline \multicolumn{2}{|l|}{ I am certain which dialysis patients are medically eligible for transplant. } & $71(60 \%)$ & $48(40 \%)$ \\
\hline \multicolumn{2}{|c|}{ The transplant educator has sufficient time to provide transplant education to all eligible patients. } & $47(43 \%)$ & $63(57 \%)$ \\
\hline \multicolumn{2}{|c|}{ I am sufficiently knowledgeable about transplant that I could answer most patients' questions. } & $58(48 \%)$ & $62(52 \%)$ \\
\hline \multicolumn{2}{|l|}{ My formal medical training adequately covered the topic of transplantation. } & $28(23 \%)$ & $93(77 \%)$ \\
\hline \multicolumn{4}{|l|}{ Quality of Available Transplant Education in Dialysis Centers } \\
\hline \multicolumn{2}{|c|}{$\begin{array}{l}\text { I am satisfied with the quality of the education materials about deceased donation that we use at our } \\
\text { center. }\end{array}$} & $53(44 \%)$ & $68(56 \%)$ \\
\hline \multicolumn{2}{|c|}{ I am satisfied with the quality of the education materials about living donation that we use at our center. } & $45(37 \%)$ & $76(63 \%)$ \\
\hline Transplant Center Partnership with Dialysis Centers & Strongly Agree/Agree & Strongly Disagree/Disagree & Don't Know \\
\hline The transplant center staff is helpful when I have a specific transplant question. & $108(82 \%)$ & $9(7 \%)$ & $14(11 \%)$ \\
\hline $\begin{array}{l}\text { Communication between dialysis and transplant centers about dialysis patients } \\
\text { undergoing transplant evaluation is poor. }\end{array}$ & $55(42 \%)$ & $60(46 \%)$ & $16(12 \%)$ \\
\hline The transplant center staff is difficult to reach. & $29(22 \%)$ & $85(65 \%)$ & $17(13 \%)$ \\
\hline \multicolumn{4}{|l|}{ Recommendations for Improvement } \\
\hline Other dialysis staff needs education about transplant themselves. & $122(93 \%)$ & $1(1 \%)$ & $8(6 \%)$ \\
\hline $\begin{array}{l}\text { I would be interested in attending a yearly in-service or continuing education } \\
\text { program to update myself about transplant. }\end{array}$ & $120(92 \%)$ & $3(2 \%)$ & $8(6 \%)$ \\
\hline Patient Drop-Out of Transplant Evaluation & Strongly Agree/Agree & Strongly Disagree/ Disagree & No Opinion \\
\hline Most patients who begin transplant evaluation will not complete it. & $30(23 \%)$ & $73(56 \%)$ & $28(21 \%)$ \\
\hline Dialysis Center Opinions About Transplant & Strongly Agree/Agree & Strongly Disagree/ Disagree & Don't Know \\
\hline $\begin{array}{l}\text { My dialysis center is supportive of eligible dialysis patients receiving transplant } \\
\text { education. }\end{array}$ & $118(90 \%)$ & $3(2 \%)$ & $10(8 \%)$ \\
\hline My dialysis center doesn't want to lose patients to transplant. & $2(1 \%)$ & $119(91 \%)$ & $10(8 \%)$ \\
\hline
\end{tabular}

Table 3: Transplant Education Barriers and Recommendations for Improvement.

There were no differences in access to educational materials between centers with varying proportions of racial/ethnic minorities. Some clinic managers (23\%) were concerned that patients would drop out of transplant evaluation, with managers in centers with larger proportions (greater than 26\%) of racial/ethnic minorities patients more likely to agree $\left(16 \%\right.$ vs. $\left.36 \%, \chi^{2}=7.94, \mathrm{p}<.05\right)$.

\section{Recommendations for improvement}

Ninety-two percent of clinic managers agreed that they would be interested in attending a yearly in-service or continuing education program to update themselves about transplant with 93\% agreeing that other dialysis staff, including transplant educators, also needed education about transplant themselves.

\section{Conclusions}

Under the National Kidney Foundation's dialysis patient bill of rights, patients have the right to receive a full explanation of all their dialysis and transplant options in words they can understand [34]. CMS transplant education mandates support of these rights by ensuring that patients are being informed of their transplant options within the first 45 days of starting dialysis and tracking their transplant referral status ongoing [7]. In the busy world of dialysis patient care, clinic managers must prioritize their staff's time to ensure that transplant education is not overlooked and that these CMS mandates are met. Other research has shown that when opinion leaders endorse key quality improvement priorities, staffs are more likely to comply with and disseminate successful interventions to patients $[26,28,35$, 36]. Unfortunately, this survey of experienced clinic managers revealed that many of their dialysis centers did not have a formal transplant education program in operation, education being repeated yearly, or an updated list of patients on the deceased donor waiting list. In addition, many managers reported that their educators did not have enough time, training, or access to quality education to be able to educate patients about transplant.
Dialysis center administrators did agree upon the value of transplant for their patients. Almost $100 \%$ felt that transplant could improve dialysis patients' health and quality-of-life, with $87 \%$ agreeing that transplant was a better option than dialysis. While other studies have shown that for-profit dialysis centers were significantly less likely to refer patients for transplant than non-profit centers [12,37], potentially due to the potential loss of dialysis revenue with transplanted patients, $91 \%$ of clinic managers disagreed with the statement, "my dialysis center did not want to lose patients to transplant."

Although these data cannot speak to how dialysis staff make decisions about which patients to educate, other research has shown that patients who are of lower socioeconomic status or who are racial/ ethnic minorities are significantly less likely to receive transplant education and referral compared to other groups $[11,12]$. One study specifically found that African-Americans on dialysis were significantly more likely to be declared psychologically unfit for transplant and not informed of their treatment options [9]. In this study, clinic managers overseeing centers with larger proportions of ethnic/racial minorities were significantly more likely to feel that their dialysis patients would drop out of transplant evaluation. This perception that minority patients are less serious about transplant may lead transplant educators to minimize educational discussion about it in dialysis centers. In this ESRD Network, although 38\% of dialysis patients were racial/ethnic minorities, only $26 \%$ of the transplants that occurred in the previous five years went to ethnic/racial minorities [33]. Other research recommends provider and healthcare system level interventions to reduce racial disparities in access to transplant including developing culturally competent education at appropriate literacy levels, establishing practice guidelines for transplant eligibility and referral, training dialysis providers how to educate patients about LDKT, standardizing educational materials across dialysis centers, and strengthening communication between transplant, dialysis, and community physicians [38]. Most of these interventions would require 
Citation: Waterman AD, Goalby C, Hyland SS, McCabe M, Dinkel KM (2012) Transplant Education Practices and Attitudes in Dialysis Centers: Dialysis Leadership Weighs In. J Nephrol Therapeutic S4:007. doi:10.4172/2161-0959.S4-007

Page 5 of 8

\begin{tabular}{|c|c|c|c|}
\hline & Yes & No & Don't know \\
\hline \multicolumn{4}{|l|}{ General Transplant Education Procedure } \\
\hline $\begin{array}{l}\text { Transplant information is provided at least once to all transplant-eligible patients, whether } \\
\text { they have expressed interest in transplant or not. }\end{array}$ & $113(86 \%)$ & $10(8 \%)$ & $8(6 \%)$ \\
\hline $\begin{array}{l}\text { Every year, all transplant-eligible patients receive transplant information, whether they have } \\
\text { expressed interest in transplant or not. }\end{array}$ & $73(56 \%)$ & $63(57 \%)$ & $18(14 \%)$ \\
\hline $\begin{array}{l}\text { There is a regularly updated list available at my dialysis center of patients on the deceased } \\
\text { donor waiting list. }\end{array}$ & $87(66 \%)$ & $62(52 \%)$ & $12(9 \%)$ \\
\hline There is a designated transplant educator. & $52(40 \%)$ & $73(56 \%)$ & $6(5 \%)$ \\
\hline There is a formal transplant education program. & $43(33 \%)$ & $77(59 \%)$ & $11(8 \%)$ \\
\hline plant education with patients) & Used with ALL patients & $\begin{array}{l}\text { Used with SOME } \\
\text { patients }\end{array}$ & $\begin{array}{l}\text { Not used/ Don't } \\
\text { know }\end{array}$ \\
\hline Patients talk with their physicians about transplant. & $64(49 \%)$ & $54(41 \%)$ & $13(10 \%)$ \\
\hline Patients talk with a social worker or other educator about transplant. & $69(53 \%)$ & $49(37 \%)$ & $13(10 \%)$ \\
\hline Patients are given handouts or brochures about transplant. & $52(40 \%)$ & $54(41 \%)$ & $25(19 \%)$ \\
\hline Patients are given all transplant center phone numbers. & $47(36 \%)$ & $51(39 \%)$ & $33(25 \%)$ \\
\hline $\begin{array}{l}\text { Patients are referred to programs discussing transplant provided by transplant centers or } \\
\text { other kidney organizations. }\end{array}$ & $29(22 \%)$ & $67(51 \%)$ & $35(27 \%)$ \\
\hline Patients are shown a video discussing transplant. & $19(14 \%)$ & $52(40 \%)$ & $60(46 \%)$ \\
\hline Patients are given a list of websites about transplant. & $17(13 \%)$ & $42(32 \%)$ & $72(55 \%)$ \\
\hline Transplant posters or information placed in the waiting room. & $31(24 \%)$ & $31(24 \%)$ & $69(53 \%)$ \\
\hline Patients are given the opportunity to talk to a kidney recipient. & $12(9 \%)$ & $39(30 \%)$ & $80(61 \%)$ \\
\hline Patients are given the opportunity to talk to a living donor. & $9(7 \%)$ & $24(18 \%)$ & $98(75 \%)$ \\
\hline $\begin{array}{l}\text { Transplant meetings are held in the dialysis center that includes patients' family member or } \\
\text { friends. }\end{array}$ & $17(13 \%)$ & $20(15 \%)$ & $94(72 \%)$ \\
\hline $\begin{array}{l}\text { Living donation meetings are held in the dialysis center for patients' family members or } \\
\text { friends. }\end{array}$ & $5(4 \%)$ & $6(5 \%)$ & $120(92 \%)$ \\
\hline
\end{tabular}

Table 4: Transplant Education Provided in Dialysis Centers.

strong buy-in by senior leadership in both dialysis and transplant to implement.

While not all dialysis centers had a formal transplant education program in operation, this study also revealed that CMS mandates could be met when these formal programs were working well. Dialysis centers with formal transplant education programs in place were significantly more likely to be having conversations with patients, distributing transplant education resources, and having better relationships with transplant center staff. It is possible that best practices from these centers could be transferred to other centers.

However, without support from nurse managers and facility administrators, transplant education provided in dialysis centers may be incomplete or provided inconsistently across patients. Educators may have insufficient time to administer transplant education, not have access to up-to-date transplant education materials, or education in multiple languages [39-41]. Also, although strong social support has been shown to increase completion of transplant evaluation [42], family members and friends were generally not invited to participate in any transplant education occurring in dialysis centers. Educational programs like home visits for extended family and friends to meet with transplant or dialysis staff [43] or video and print programs discussing living donation possibilities that can be shared with patients' families [44] may be helpful in engaging the patients' social support networks fully in transplant and living donation decision-making.

However, before concluding anything about deficiencies in dialysis clinic managers' transplant education practices, we must step back to examine the entire field of ESRD patient care. The majority of clinic managers expressed interest in continuing education about transplant for themselves and their staff. As the healthcare partner most benefiting from increased transplant revenue, transplant centers play a critical role in transplant education occurring within dialysis centers. Over onethird of clinic managers reported that communication with transplant center staff was poor and over half were unsatisfied with available transplant education. Transplant centers could help clinic managers by determining which patients are potential candidates for transplant, providing quality transplant education, and facilitating successful transplant evaluation. More frequent outreach efforts by transplant centers could also help to address more complex patient questions and concerns about transplant.

After examining dialysis managers' attitudes and programmatic approaches to conducting transplant education within dialysis centers, the next obvious step is to survey the transplant educators themselves to understand what is occurring with their patients. It will also be important to learn whether educators, themselves have sufficient training in transplant and practical educational resources to be able to answer patients' questions. Changes in transplant education practices within dialysis centers after the transplant-related CMS Conditions for Coverage were expanded will also be important. When providing outreach to dialysis centers, transplant centers face barriers that need further identification and study. Finally, we need to understand what dialysis patients actually know about transplant, what education they received, and whether they are truly making informed choices.

Dialysis and transplant leadership have the same agenda - to ensure excellent care of patients with kidney failure. Improving transplant education in dialysis centers is one way to increase patients' pursuit of a treatment option that has proven effectiveness in improving health and quality-of-life. Improved education may also reduce disparities in medical care and national healthcare costs. However, unless dialysis 
Citation: Waterman AD, Goalby C, Hyland SS, McCabe M, Dinkel KM (2012) Transplant Education Practices and Attitudes in Dialysis Centers: Dialysis Leadership Weighs In. J Nephrol Therapeutic S4:007. doi:10.4172/2161-0959.S4-007

Page 6 of 8

corporations implement specific transplant education policies and procedures, transplant centers support these initiatives, and CMS ensures compliance, the barriers to transplant education identified in this study will persist.

\section{Acknowledgements}

We appreciate the opportunity provided to us by the Heartland Kidney Network (ESRD Network 12) to survey dialysis administrators in lowa, Kansas, Missouri, and Nebraska.

Funding Sources: This research was supported by Health Resources and Services Administration, Division of Organ Transplantation (R39OT10582). There are no conflicts of interests for any of the authors.

\section{References}

1. Bartlett ST, Farney AC, Jarrell BE, Philosophe B, Colonna J O, et al. (1998) Kidney transplantation at the University of Maryland. Clin Transpl 177-185

2. Christensen A, Holman J, Turner C, Slaughter J (1989) Quality of life in endstage renal disease: Influence of renal transplantation. Clinical Transplantation 3: $46-53$

3. Neipp M, Karavul B, Jackobs S, Meyer zu Vilsendorf A, Richter N, et al. (2006) Quality of life in adult transplant recipients more than 15 years after kidney transplantation. Transplantation 81: 1640-1644

4. Loubeau PR, Loubeau JM, Jantzen R (2001) The economics of kidney transplantation versus hemodialysis. Progress in Transplantation 11: 291-297.

5. Matas AJ, Schnitzler M, Daar AS (2004) Payment for living kidney donors (vendors) is not an abstract ethical discussion occurring in a vacuum. American Journal of Transplantation 4: 1380-1381.

6. Yen EF, Hardinger K, Brennan DC, Woodward RS, Desai, NM, et al. (2004) Cost-effectiveness of extending Medicare coverage of immunosuppressive medications to the life of a kidney transplant. American Journal of Transplantation 4: 1703-1708.

7. Centers for Medicare \& Medicaid Services: CMS (2008) Medicare and Medicaid Programs Conditions for Coverage for End-Stage Renal Disease Facilities Final Rule, Department of Health and Human Services, ed 73.

8. Conte A, Fabregas L (2009) Kidney waitlists often miss target. Pittsburgh Tribune-Review.

9. Kucirka LM, Grams ME, Balhara KS, Jaar BG, Segev DL (2012) Disparities in provision of transplant information affect access to kidney transplantation. American Journal of Transplantation 12: 351-357

10. Waterman $A D$, Barrett $A C$, Stanley SL, Rothstein M, Burroughs TE, et al (2006) Why African-Americans are not pursuing living kidney donation. World Transplant Congress American Journal of Transplantation 82: 268.

11. Alexander GC, Sehgal AR (1998) Barriers to cadaveric renal transplantation among blacks, women, and the poor. JAMA 280: 1148-1152.

12. Garg PP, Frick KD, Diener-West M, Powe NR (1999) Effect of the ownership of dialysis facilities on patients' survival and referral for transplantation. New England Journal of Medicine 341: 1653-1660.

13. van Ryn M, Fu SS (2003) Paved with good intentions: Do public health and human service providers contribute to racial/ethnic disparities in health? American Journal of Public Health 93: 248-255.

14. Cooper-Patrick L, Gallo JJ, Gonzales JJ, Vu HT, Powe NR et al. (1999) Race gender, and partnership in the patient-physician relationship. JAMA 282: 583589

15. Miskulin D (2007) Case-mix factors explain the survival advantage of Hispanic and racial minority patients on hemodialysis. Nature Clinical Practice Nephrology 3: 192-193.

16. Robinson BM, Joffe MM, Pisoni RL, Port FK, Feldman HI (2006) Revisiting survival differences by race and ethnicity among hemodialysis patients: The Dialysis Outcomes and Practice Patterns Study. Journal of the American Society of Nephrology 17: 2910-2918.

17. Goovaerts T, Jadoul M, Goffin E (2005) Influence of a pre-dialysis education programme (PDEP) on the mode of renal replacement therapy. Nephrology Dialysis Transplantation 20: 1842-1847.

18. King K, Witten B, Matkin-Grumke J, Whitlock RW, Waterman AW (2008) The Missouri Kidney Program's Patient Education Program: A 12-year Retrospective Analysis. Nephrology News and Issues: 44-54.

19. National Kidney Foundation (2009) Kidney Transplant. In: National Kidney Foundation ed. 2006 ed. New York, NY.

20. National Kidney Foundation (2000) 25 Facts about organ donation and transplantation.

21. Pradel F, Suwannaprom P, Mullins C, Sadler J, Bartlett S (2008) Short-term impact of an educational program promoting live donor kidney transplantation in dialysis centers. Progress in Transplantation 14: 263-272.

22. Schweitzer EJ, Yoon S, Hart J, Anderson L, Barnes R, et al. (1997) Increased living donor volunteer rates with a formal recipient family education program. American Journal of Kidney Disease 29: 739-745.

23. Rodrigue JR, Cornell DL, Lin JK, Kaplan B, Howard RJ (2007) Increasing live donor kidney transplantation: a randomized controlled trial of a home-based educational intervention. American Journal of Transplantation 7: 394-401.

24. Rodrigue JR, Cornell DL, Kaplan B, Howard RJ (2008) A randomized trial of a home-based educational approach to increase live donor kidney transplantation: Effects in blacks and whites. American Journal of Kidney Disease 51: 663-670.

25. Anderson CD, Vachharajani N, Doyle M, Lowell JA, Wellen JR, et al. (2008) Advanced donor age alone does not affect patient or graft survival after live transplantation. Journal of the American College of Surgeons 207: 847-852.

26. Sehgal AR (2002) Improving hemodialysis patient outcomes: a step-by-step approach. Seminars in Dialysis 15: 35-37.

27. Weiner BJ, Shortell SM, Alexander J (1997) Promoting clinical involvement in hospital quality improvement efforts: The effects of top management, board and physician leadership. Health Services Research 32: 491-510.

28. Duckers ML, Stegeman I, Spreeuwenberg P, Wagner C, Sanders K, et al. (2009) Consensus on the leadership of hospital CEOs and its impact on the participation of physicians in improvement projects. Health Policy 91: 306-313.

29. United States Renal Data System (2010) USRDS 2010 Annual Report: Atlas of Chronic Kidney Disease and End-Stage Renal Disease in the United States.

30. United States Renal Data System (2011) USRDS 2011 Annual Report: Atlas of Chronic Kidney Disease and End-Stage Renal Disease in the United States.

31. Waterman A, Robbins M, Paiva A, Hyland SS (2010) Kidney patients' intention to receive a deceased donor transplant: Development of stage of change, decisional balance, and self-efficacy measures. J Health Psychol 15: 436-445.

32. United States Renal Data System (2009) USRDS 2009 Annual Report: Atlas of Chronic Kidney Disease and End-Stage Renal Disease in the United States.

33. Advanced data reports (2010) Organ Procurement and Transplantation Network (OPTN)

34. National Kidney Foundation (2003) Dialysis Patients' Bill of Rights and Responsibilities. In: Naitonal Kidney Foundation ed. New York.

35. Doumit G, Gattellari M, Grimshaw J, O’Brien MA (2007) Local opinion leaders: Effects on professional practice and health care outcomes. Cochrane Database Syst Rev 1: CD000125

36. Berner ES, Baker CS, Funkhouser E, Heudebert GR, Allison JJ, et al. (2003) Do local opinion leaders augment hospital quality improvement efforts? A randomized trial to promote adherence to unstable angina guidelines. Med Care 41: 420-431.

37. Josefson D (1999) Patients dialysed at for-profit centres do worse. BMJ 319 1517

38. Waterman AD, Rodrigue JR (2010) Ethically and effectively advancing living donation: How should it be done? In: Understanding organ donation: Applied behavioral science perspectives. Wiley-Online Library.

39. Maiorano A, Schena FP (2008) The dynamics of kidney donation: Viewpoints 
Citation: Waterman AD, Goalby C, Hyland SS, McCabe M, Dinkel KM (2012) Transplant Education Practices and Attitudes in Dialysis Centers: Dialysis Leadership Weighs In. J Nephrol Therapeutic S4:007. doi:10.4172/2161-0959.S4-007

from the donor, the recipients, and the transplant team. Kidney International 73: $1108-1110$

40. Murray LR, Conrad NE, Bayley EW (1999) Perceptions of kidney transplant by persons with end stage renal disease. American Nurses Nephrology Association Journal 26: 479-483.

41. Conesa C, Rios A, Ramirez P, Sanchez J, Sanchez E, et al. (2005) Attitude of primary care nurses toward living kidney donation. Transplantation Proceedings 37: $3626-3630$.

42. Clark CR, Hicks LS, Keogh JH, Epstein AM, Ayanian JZ (2008) Promoting access to renal transplantation: The role of social support networks in completing pre-transplant evaluations. Journal of General Internal Medicine 23: $1187-1193$

43. Rodriguez J, Cornell DL, Kaplan B, Howard RJ (2008) A randomized trial of a home-based educational approach to increase live donor kidney transplantation: Effects in blacks and whites. American Journal of Kidney Diseases 51: 663-670.

44. Hays R, Waterman AD (2008) Improving preemptive transplant education to increase living donation rates: reaching patients earlier in their disease adjustment process. Progress in Transplantation 18: 1-6.

This article was originally published in a special issue, Kidney

Transplantation handled by Editor(s). Dr. Gagangeet Sandhu, Columbia

University College of Physicians and Surgeons, USA; Dr. Krista Lentine, Saint

Louis University School of Medicine, USA 